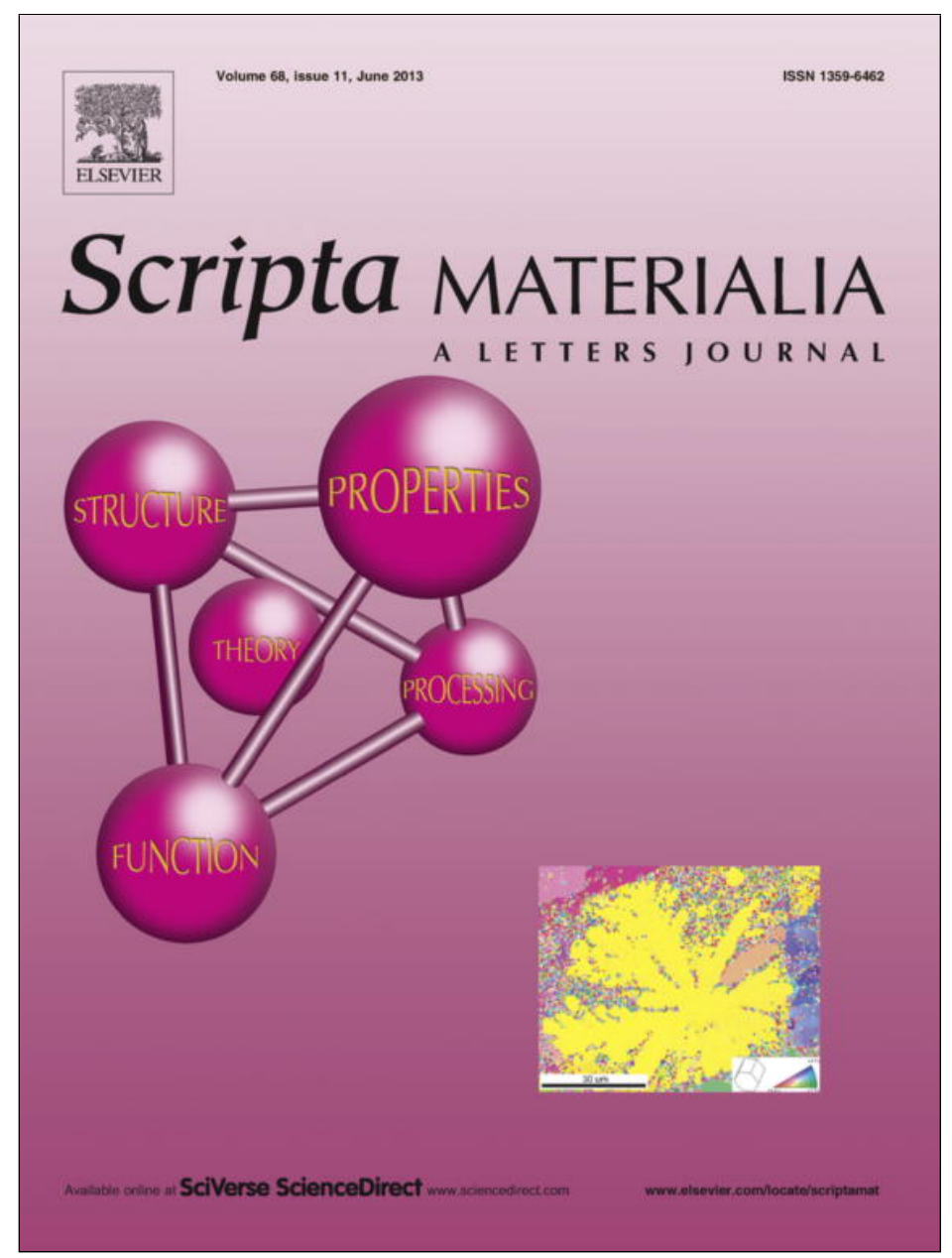

This article appeared in a journal published by Elsevier. The attached copy is furnished to the author for internal non-commercial research and education use, including for instruction at the authors institution and sharing with colleagues.

Other uses, including reproduction and distribution, or selling or licensing copies, or posting to personal, institutional or third party websites are prohibited.

In most cases authors are permitted to post their version of the article (e.g. in Word or Tex form) to their personal website or institutional repository. Authors requiring further information regarding Elsevier's archiving and manuscript policies are encouraged to visit:

http://www.elsevier.com/authorsrights 


\title{
Enhanced strength and transformation-induced plasticity in rapidly solidified $\mathrm{Zr}-\mathrm{Co}-(\mathrm{Al})$ alloys
}

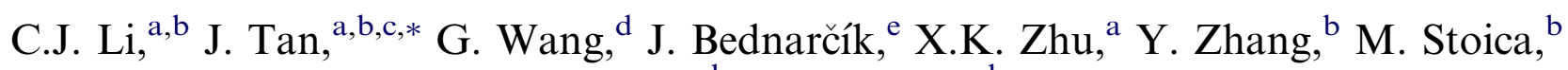 \\ U. Kühn ${ }^{\mathrm{b}}$ and J. Eckert ${ }^{\mathrm{b}, \mathrm{c}}$ \\ ${ }^{a}$ School of Materials Science and Engineering, Kunming University of Science and Technology, 650093 Kunming, China \\ ${ }^{\mathrm{b}}$ IFW Dresden, Institute for Complex Materials, P.O. Box 2701 16, D-01171 Dresden, Germany \\ ${ }^{\mathrm{c}}$ TU Dresden, Institute of Materials Science, D-01062 Dresden, Germany \\ ${ }^{\mathrm{d}}$ Laboratory for Microstructures, Shanghai University, 200444 Shanghai, China \\ ${ }^{\mathrm{e}}$ HAS YLAB at DESY, Notkestr. 85, D-22603 Hamburg, Germany
}

Received 5 November 2012; revised 11 February 2013; accepted 12 February 2013

Available online 21 February 2013

\begin{abstract}
Transformation-induced plasticity and significant work-hardening capability were verified to be an effective way to enhance the performance of materials. This work reports on $\mathrm{Z}_{49} \mathrm{Co}_{49} \mathrm{Al}_{2}$ alloy obtained by traditional water-cooled copper mold casting with high strength and large plasticity due to B2-to-B33 deformation-induced martensitic transformation. The B33 martensite with orthorhombic structure does not form spontaneously above room temperature in $\mathrm{Zr}-\mathrm{Co}-(\mathrm{Al})$ alloys, except when it is induced by local stress concentration.
\end{abstract}

(c) 2013 Acta Materialia Inc. Published by Elsevier Ltd. All rights reserved.

Keywords: Suction casting; Compression test; Bulk amorphous composites; Transformation-induced plasticity

Rapid solidification techniques for chilling metallic liquids at very high rates allow freezing of the configuration of alloy melts and obtaining bulk metallic glass (BMG) for some alloys. When the cooling rate is not sufficiently high to obtain a fully amorphous alloy, BMG composites, nanocrystalline material or ultrafine-grained (UFG) material can be obtained, depending on the glass-forming ability (GFA) of the respective alloy [1]. The rapid solidification processing results in increased strength, as well as enhanced fracture and fatigue resistance, with concurrent improvements in mechanical, physical and chemical properties [2,3]. The deformation of BMG at room temperature is highly localized into shear bands, owing to strain softening and/or thermal softening [4]. Finally, they develop towards catastrophic failure along one dominant shear plane, thus restricting wide application of BMG [5-7]. Many desired mechanical properties, however, can be achieved from either in situ or ex situ BMG composites

\footnotetext{
* Corresponding author at: School of Materials Science and Engineering, Kunming University of Science and Technology, 650093 Kunming, China. Tel.: +86 871 65107512; fax: +86 871 65107922; email: tanjuncn@gmail.com
}

by controlling the type, size, volume fraction and/or distribution of the second phase dispersions [6-10].

Transformation-induced plasticity and significant work-hardening capability have been found in Ti-based [9-11] and Zr-based [12-18] composites and are verified to be an effective way to enhance the performance of materials $[2,19]$. Nevertheless, most of the Ti- and $\mathrm{Zr}-$ based BMG and their composites often require the addition of copper, nickel or beryllium, which makes these alloys less suitable to be used as biomedical implants. Recently, the discovery of $\mathrm{Zr}-\mathrm{Co}-\mathrm{Al}$ ternary alloys with superior corrosion resistance and good bioactivity has renewed interest in this type of glass-forming alloy $[20,21]$.

$\mathrm{ZrCo}$ alloys with $\mathrm{B} 2$ ( $\mathrm{CsCl}$ structure) are inherently ductile, owing to the existence of a mechanically induced B2-to-B33 martensitic transformation [14]. However, monolithic crystalline phases are often soft, despite obvious strain-hardening, as observed in both compressive and tensile tests $[14,18]$. A possible way to obtain both high strength and high plasticity is to combine the ductile B2 phase with bulk amorphous/nanograined/UFG phase(s) through rapid solidification methods. $\mathrm{ZrCo}$ alloys alloyed with low-cost aluminum are good candidates to verify this conjecture. In the present study, a 
$\mathrm{Zr}_{49} \mathrm{Co}_{49} \mathrm{Al}_{2}$ alloy was produced by traditional watercooled copper mold casting, which exhibits a nominal maximum compression strength of $2260 \mathrm{MPa}$, together with an ultimate true failure strain of $69 \%$, owing to deformation-induced martensite formation.

$\mathrm{Zr}_{49} \mathrm{Co}_{49} \mathrm{Al}_{2}, \mathrm{Zr}_{50} \mathrm{Co}_{50}$ and $\mathrm{Zr}_{56} \mathrm{Co}_{28} \mathrm{Al}_{16}$ (nominal composition in atomic per cent) pre-alloys were synthesized by arc-melting the proper amounts of the constituting elements (purity of $99.99 \%$ or higher) in a Ti-gettered high purity argon atmosphere. The pre-alloy ingots were remelted at least four times in order to ensure chemical homogeneity. The ingots were cut into small pieces with a mass of $\sim 5-6 \mathrm{~g}$, and then they were melted and cast into cylindrical rods with diameter $2 \mathrm{~mm}$ and length $\sim 50 \mathrm{~mm}$, using water-cooled copper mold suction casting. The structure and the thermal behavior were checked by X-ray diffraction (XRD) and differential scanning calorimetry (DSC). Low-temperature magnetometry was performed using a superconducting quantum interference device (SQUID). Compression tests (height-to-diameter ratio 2:1) were performed using an Instron 5869 testing machine equipped with a laser extensometer (Fiedler) at a constant strain rate of $0.0005 \mathrm{~s}^{-1}$ at room temperature. Micro-indentation was carried out at at least 15 points on each of the samples, using a Vickers diamond indenter and a load of $25 \mathrm{~g}$ with a dwell time of $10 \mathrm{~s}$. The morphology and the atomic-level structure of the sample were investigated using high-resolution scanning electron microscopy (Gemini 1530) and field emission transmission electron microscopy (JEM 2010F). The deformation behavior was also investigated by high-energy XRD $\left(\lambda=0.020728 \mathrm{~nm}\right.$, beam size $\left.0.6 \times 0.6 \mathrm{~mm}^{2}\right)$ at the P02.1 beam line of PETRA III (Hamburg, Germany)

Figure 1 depicts the mechanical properties of the $\mathrm{Zr}_{49} \mathrm{Co}_{49} \mathrm{Al}_{2}$ alloy at room temperature, revealing high nominal compression strength, which is as high as that of $\mathrm{Zr}_{56} \mathrm{Co}_{28} \mathrm{Al}_{16}$ BMG obtained under the same condi-
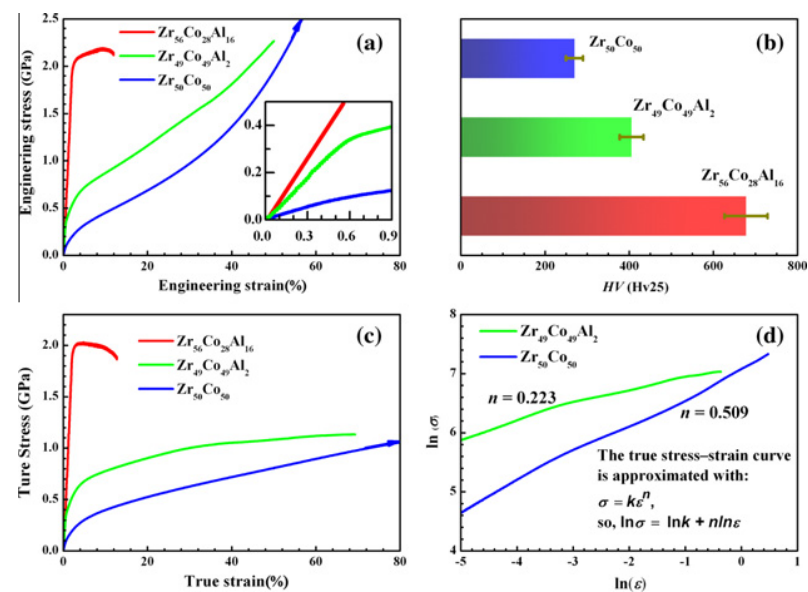

Figure 1. (Color online) Mechanical properties of the $\mathrm{Zr}-\mathrm{Co}-\mathrm{Al}$ alloys at room temperature. (a) Typical compressive engineering stress-strain curves of alloy rods with diameter $2 \mathrm{~mm}$. The inset shows an enlarged part of the stress-strain curves. (b) Vickers hardness (Hv) of alloys. (c) Typical compressive true stress-true strain curves of the alloy rods revealing pronounced work-hardening behavior for $\mathrm{Zr}_{49} \mathrm{Co}_{49} \mathrm{Al}_{2}$ and $\mathrm{Zr}_{50} \mathrm{Co}_{50}$ alloys. (d) The natural logarithm curves of the true stresstrue strain indicate the change in working-hardening rate. tions by water-cooled copper mold casting [21-24], as shown in Figure 1a. The nominal compression strength of $\mathrm{Zr}_{49} \mathrm{Co}_{49} \mathrm{Al}_{2}$ is $\sim 2260 \mathrm{MPa}$ combined with $>50 \%$ ultimate failure strain. For comparison, $\mathrm{Zr}_{50} \mathrm{Co}_{50}$ alloy rods were prepared. For these rods, an engineering strain as large as $\sim 80 \%$ was achieved. As a result of such intense deformation, the rods were compressed into thin pellets without fracturing. Such results agree well with previous research in that the $\mathrm{B} 2 \mathrm{ZrCo}$ alloy is inherently ductile [14]. The inset in Figure 1a shows an enlarged part of the stress-strain curves. The $0.2 \%$ offset yield strength $\left(\sigma_{\mathrm{y}}\right)$ and the Young's modulus $(E)$ of the different alloys are listed in Table 1. The results reveal that the yield strength $\left(\sigma_{\mathrm{y}}\right)$ apparently increases upon minor addition of Al. Addition of 2 at. $\% \mathrm{Al}$ improves $\sigma_{\mathrm{y}}$ almost three times compared with $\mathrm{Zr}_{50} \mathrm{Co}_{50}$ rods, i.e., $\sigma_{\mathrm{y}}$ increases from 122 to $378 \mathrm{MPa}$. The Young's modulus $(E)$ increases significantly from $18 \pm 2 \mathrm{GPa}$ to $64 \pm 2 \mathrm{GPa}$. For fully amorphous $\mathrm{Zr}_{56} \mathrm{Co}_{28} \mathrm{Al}_{16} \mathrm{BMG}$, the Young's modulus $(E)$ is $92 \pm 2 \mathrm{GPa}$. Hence, the minor addition of $\mathrm{Al}$ inevitably affects the topological and/or chemical structure of the alloys. Actually, an attractive force originates from the difference in electronegativity between the elements and is reflected in the heat of mixing, as shown in Table 2. Elements with stronger attractive force exhibit a larger enthalpy of mixing, which favors the formation of a highly dense random packed structure in which the diffusivity of the constituent elements is suppressed $[1,25]$. Thus, good GFA and/or high thermal stability can be more easily synthesized for Al-containing amorphous alloys [26].

The Vickers hardness $(H v)$ increases from $270 \mathrm{HV} 25$ to $406 \mathrm{HV} 25$, owing to the minor addition of $\mathrm{Al}$ element, indicating that the atomic bonding strength improves and thus leads to improvements in the elastic modulus and yield strength. The highly dense random packed structure of fully amorphous $\mathrm{Zr}_{56} \mathrm{Co}_{28} \mathrm{Al}_{16} \mathrm{BMG}$ shows higher Vickers hardness, elastic modulus and yield strength, as shown in Figure 1b.

The pronounced significant work-hardening behavior of the $\mathrm{Zr}_{49} \mathrm{Co}_{49} \mathrm{Al}_{2}$ and $\mathrm{Zr}_{50} \mathrm{Co}_{50}$ alloys is illustrated in Figure 1c and d. However, no strain-hardening behavior was observed for $\mathrm{Zr}_{56} \mathrm{Co}_{28} \mathrm{Al}_{16}$ BMG [21]. The workhardening behavior of these samples was analyzed by means of the work-hardening index $n$, defined as [27]: $\sigma=k \varepsilon^{n}$, where $\sigma$ represents the applied stress on the material, $\varepsilon$ is the strain, and $k$ is the strength coefficient. The value of the work-hardening index $n$ lies between 0 and 1 . A value of 0 means that a material is a perfectly plastic solid; while an $n$ value of 1 represents a $100 \%$ elastic solid [27]. Most metals have an $n$ value between 0.10 and 0.50 , as shown in Table 3. The $\mathrm{Zr}_{49} \mathrm{Co}_{49} \mathrm{Al}_{2}$ alloy has a larger $n$ value, exceeding most metals, including annealed low-carbon steel, aluminum alloys and magnesium alloys, while $\mathrm{Zr}_{50} \mathrm{Co}_{50}$ has an $n$ value of 0.509 , which is higher than that of annealed 304 stainless steel [27]. The martensitic transformation in 304 stainless steel can be induced by plastic deformation at room temperature, and thus leads to obvious work-hardening behavior [28]. Therefore, it is possible to assume that the present $\mathrm{Zr}$-Co-based alloys also undergo a deformationinduced transformation, leading to the large work-hardening index $(n)$. Investigating the structural evolution 
Table 1. Mechanical properties including the yield stress $\left(\sigma_{\mathrm{y}}\right)$, Young's modulus $(E)$, ultimate compressive strength (UCS), strength coefficient $(k)$ and work-hardening index $(n)$ of $\mathrm{Zr}-\mathrm{Co}-\mathrm{Al} \mathrm{BMG}$ and/or their composites obtained by monotonic compression test.

\begin{tabular}{llllll}
\hline Alloys & $\sigma_{\mathrm{y}}(\mathrm{MPa})$ & $E(\mathrm{GPa})$ & $\mathrm{UCS}(\mathrm{GPa})$ & $K(\mathrm{MPa})$ & $n$ \\
\hline $\mathrm{Zr}_{49} \mathrm{Co}_{49} \mathrm{Al}_{2}$ & $378 \pm 20$ & $64 \pm 2$ & $2.26 \pm 0.02$ & 458 & 0.223 \\
$\mathrm{Zr}_{50} \mathrm{Co}_{50}$ & $122 \pm 20$ & $18 \pm 2$ & - & $2.1 \pm 0.1$ & $-R^{2}$ \\
$\mathrm{Zr}_{56} \mathrm{Co}_{28} \mathrm{Al}_{16}$ & $1897 \pm 20$ & $92 \pm 2$ & $2.1 \pm 09$ & - \\
\hline
\end{tabular}

Table 2. Enthalpy of mixing and the atomic radius in the $\mathrm{Zr}-\mathrm{Co}-\mathrm{Al}$ system.

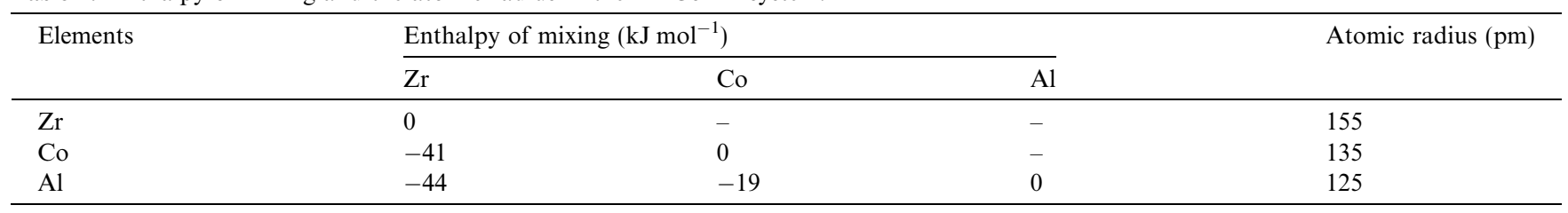

Table 3. Tabulation of $n$ and $k$ values for several alloys.

\begin{tabular}{|c|c|c|c|}
\hline Alloys & $n$ & $k(\mathrm{MPa})$ & References \\
\hline $\mathrm{Zr}_{50} \mathrm{Co}_{50}$ & 0.509 & 113 & This work \\
\hline $\mathrm{Zr}_{49} \mathrm{Co}_{49} \mathrm{Al}_{2}$ & 0.223 & 458 & This work \\
\hline Low-carbon steel (annealed) & 0.21 & 600 & {$[27]$} \\
\hline 4340 steel (tempered at $315^{\circ} \mathrm{C}$ ) & 0.12 & 2650 & {$[27]$} \\
\hline 304 stainless steel (annealed) & 0.44 & 1400 & {$[27]$} \\
\hline Copper (annealed) & 0.44 & 530 & {$[27]$} \\
\hline Naval brass (annealed) & 0.21 & 585 & {$[27]$} \\
\hline 2024 aluminum alloy (heat treated-T3) & 0.17 & 780 & {$[27]$} \\
\hline AZ31B magnesium alloy (annealed) & 0.16 & 450 & {$[27]$} \\
\hline
\end{tabular}

upon compressive testing may provide direct evidence for this assumption.

The cross-sectional surfaces of the as-cast $\mathrm{Zr}_{50} \mathrm{Co}_{50}$ and $\mathrm{Zr}_{49} \mathrm{Co}_{49} \mathrm{Al}_{2}$ alloy rods were further checked by XRD, indicating that the rapidly solidified alloys are mainly composed of the B2 ZrCo phase within the resolution limits of XRD. However, a small amount of B33 ZrCo phase, marked with the symbol "_" in Figure 2, was detected on the cross-sectional surfaces of the deformed $\mathrm{Zr}_{50} \mathrm{Co}_{50}$ alloy rod. The XRD patterns shown in Figure $2 \mathrm{a}$ and $\mathrm{b}$ reveal a B2-to-B33 martensitic transformation under compression. However, there is no remarkable transformation on both the upper and lower surfaces of the specimens compared with the as-cast specimen shown in Figure 2c. This indicates that the $\mathrm{Zr}_{50} \mathrm{Co}_{50}$ alloy

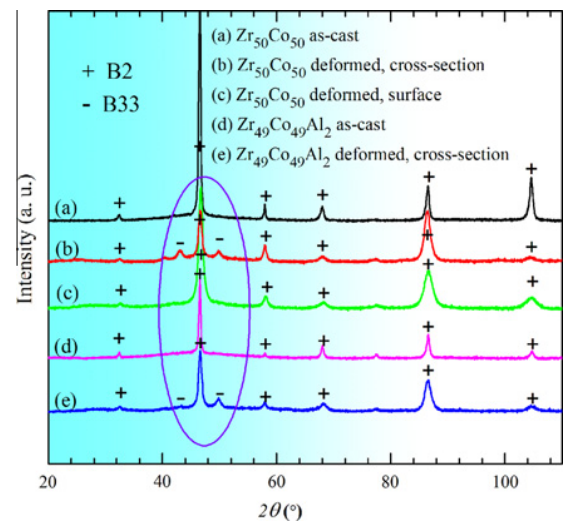

Figure 2. (Color online) The existence of martensitic transformation in $\mathrm{Zr}-\mathrm{Co}$-based alloys, owing to stress concentration. The structure evolution of the as-cast and deformed alloys indicates a B2-to-B33 martensitic transformation upon compression testing. contains a distribution of a second phase with an orthorhombic (B33) structure whose composition is identical to that of the matrix, which stems from a martensitic transformation induced by local stress concentration. It is proposed that this transformation contributes to the unusually good ductility of the alloy. The results are consistent with the investigations on $\mathrm{Zr}_{50} \mathrm{Co}_{40} \mathrm{Ni}_{10}$ [29]. The cross-sectional surface of the as-cast $\mathrm{Zr}_{49} \mathrm{Co}_{49} \mathrm{Al}_{2}$ alloy rod is composed mainly of $\mathrm{B} 2 \mathrm{ZrCo}$ phase, shown in Figure $2 \mathrm{~d}$. A small volume fraction of $\mathrm{B} 33 \mathrm{ZrCo}$ phase and the remaining B2 ZrCo phase, shown in Figure 2e, were also detected on the cross-sectional surfaces of the deformed $\mathrm{Zr}_{49} \mathrm{Co}_{49} \mathrm{Al}_{2}$ alloy rod. The result from high-energy XRD, shown in Figure 3, further confirmed the fact. It is suggested that the production of a small quantity of martensite in the vicinity of a crack tip may help to ductilize $\mathrm{Zr}_{50} \mathrm{Co}_{50}$ and $\mathrm{Zr}_{49} \mathrm{Co}_{49} \mathrm{Al}_{2}[30,31]$.

Figure 4 shows the temperature dependence of the magnetic moment of the as-cast $\mathrm{Zr}_{49} \mathrm{Co}_{49} \mathrm{Al}_{2}$ alloy measured by SQUID magnetometry. The intensity of magnetization is very low, so the sample remains in the

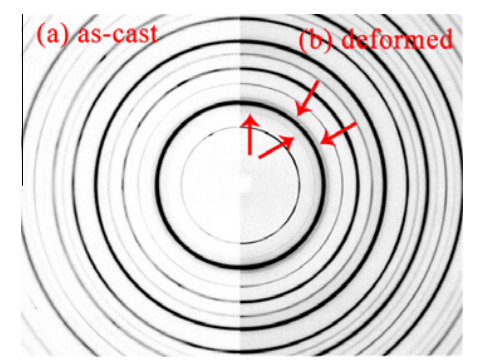

Figure 3. (Color online) Comparison of the two-dimensional high energy XRD patterns of (a) as-cast and (b) deformed $\mathrm{Zr}_{49} \mathrm{Co}_{49} \mathrm{Al}_{2}$ alloy. The red arrows indicate the weak structural changes after deformation. 


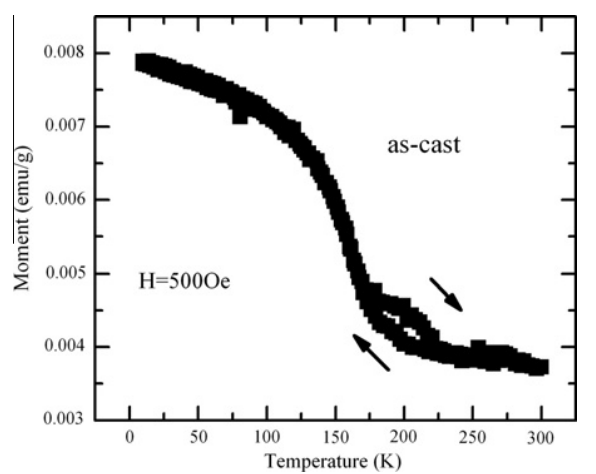

Figure 4. Temperature dependence of the magnetic moment of the ascast $\mathrm{Zr}_{49} \mathrm{Co}_{49} \mathrm{Al}_{2}$ alloy measured by SQUID magnetometry, revealing a small thermal hysteresis due to martensitic transformation $\sim 200 \mathrm{~K}$.

paramagnetic state during the domain of temperature investigated. However, the intensity in the low-temperature regime is slightly higher. This may be because of low temperature thermal fluctuations of the magnetic moment rotation. At $\sim 200 \mathrm{~K}$, the existence of a small thermal hysteresis may be attributed to the martensitic transformation. These findings are similar to previous work on $\mathrm{Zr}-\mathrm{Co}-\mathrm{Ni}$ alloys, where the B33 (orthorhombic) and $\mathrm{B} 2(\mathrm{CsCl})$ structures are stable $<240 \mathrm{~K}$ and $>390 \mathrm{~K}$, respectively, with a domain of coexistence of the two phases in-between [30,31]. The shift in the temperature might be attributed to the addition of $\mathrm{Al}$ to the alloys.

In conclusion, a $\mathrm{Zr}_{49} \mathrm{Co}_{49} \mathrm{Al}_{2}$ alloy with high compression strength and plasticity was obtained by watercooled copper mold casting. B33 martensite (orthorhombic structure) does not form spontaneously above room temperature in the investigated $\mathrm{Zr}-\mathrm{Co}-(\mathrm{Al})$ alloys except when it is induced by local stress concentration. The alloy contains a distribution of a second phase with an orthorhombic (B33) structure whose composition is identical to that of the matrix, which stems from a martensitic transformation induced by local stress concentration. It is proposed that this transformation contributes to the good ductility of the alloy.

The authors thank S. Donath, M. Frey, B. Opitz, U. Wilke, B. Bartusch, J. Liu and Q. Luo for technical assistance and stimulating discussions. C.J.L and J.T would like to acknowledge the fellowship support from the China Scholarship Council. Additional support provided by the German Science Foundation under the Leibniz Program (Grant EC 111/26-1), the Science Foundation of the Yunnan Provincial Science and Technology Department (Grant 2011FB021) and the Science Foundation of the Yunnan Provincial Education Department (Grant 2010Z012) is also gratefully acknowledged. G.W. is also grateful for financial support from the NSF of China (Nos. 51171098 and 50731008), the Shanghai Pujiang Program (No. 11PJ1403900), the Innovation Program of Shanghai Municipal Education Commission (No. 12ZZ090), and the Program for Professor of Special Appointment (Eastern Scholar) at Shanghai Institutions of Higher Learning.
[1] W.H. Wang, C. Dong, C.H. Shek, Mater. Sci. Eng. R 44 (2004) 45-89.

[2] D.C. Hofmann, Science 329 (2010) 1294-1295.

[3] M.M. Trexler, N.N. Thadhani, Prog. Mater Sci. 55 (2010) $759-839$.

[4] J.J. Lewandowski, A.L. Greer, Nat. Mater. 5 (2006) 1518.

[5] G. Wang, N. Mattern, J. Bednarčík, R. Li, B. Zhang, J. Eckert, Acta Mater. 60 (2012) 3074-3083.

[6] B.A. Sun, S. Pauly, J. Tan, M. Stoica, W.H. Wang, U. Kühn, J. Eckert, Acta Mater. 60 (2012) 4160-4171.

[7] J. Eckert, J. Das, S. Pauly, C. Duhamel, J. Mater. Res. 22 (2007) 285-301.

[8] J.W. Qiao, Y. Zhang, P.K. Liaw, G.L. Chen, Scr. Mater. 61 (2009) 1087-1090.

[9] Y.S. Oh, C.P. Kim, S. Lee, N.J. Kim, Acta Mater. 59 (2011) 7277-7286.

[10] C.P. Kim, Y.S. Oh, S. Lee, N.J. Kim, Scr. Mater. 65 (2011) 304-307.

[11] C.P. Frick, T.W. Lang, K. Spark, K. Gall, Acta Mater. 54 (2006) 2223-2234.

[12] S. Pauly, S. Gorantla, G. Wang, U. Kühn, J. Eckert, Nat. Mater. 9 (2010) 473-477.

[13] Y. Wu, Y. Xiao, G. Chen, C.T. Liu, Z. Lu, Adv. Mater. 22 (2010) 2770-2773.

[14] Y. Kaneno, K. Asao, M. Yoshida, H. Tsuda, T. Takasugi, J. Alloys Compd. 456 (2008) 125-134.

[15] M. Matsuda, T. Nishimoto, K. Matsunaga, Y. Morizono, S. Tsurekawa, M. Nishida, J. Mater. Sci. 46 (2011) 42214227.

[16] M. Matsuda, T. Nishimoto, Y. Morizono, S. Tsurekawa, M. Nishida, Intermetallics 19 (2011) 894-899.

[17] J.A. Wollmershauser, C.J. Neil, S.R. Agnew, Metall. Mater. Trans. A 41 (2010) 1217-1229.

[18] T. Yamaguchi, Y. Kaneno, T. Takasugi, Scr. Mater. 52 (2005) 39-44.

[19] J. Liu, T. Gottschall, K.P. Skokov, J.D. Moore, O. Gutfleisch, Nat. Mater. 11 (2012) 620-626.

[20] T. Wada, F. Qin, X. Wang, M. Yoshimura, A. Inoue, N. Sugiyama, R. Ito, N. Matsushita, J. Mater. Res. 24 (2009) 2941-2948.

[21] J. Tan, Y. Zhang, M. Stoica, U. Kühn, N. Mattern, F.S. Pan, J. Eckert, Intermetallics 19 (2011) 567-571.

[22] J. Tan, Y. Zhang, B.A. Sun, M. Stoica, C.J. Li, K.K. Song, U. Kuhn, F.S. Pan, J. Eckert, Appl. Phys. Lett. 98 (2011) 151906.

[23] J. Tan, F.S. Pan, Y. Zhang, Z. Wang, M. Stoica, B.A. Sun, U. Kühn, J. Eckert, Mater. Sci. Eng., A 539 (2012) 124-127.

[24] J. Tan, F.S. Pan, Y. Zhang, B.A. Sun, J. He, N. Zheng, M. Stoica, U. Kühn, J. Eckert, Intermetallics 31 (2012) 282-286.

[25] W.H. Wang, Prog. Mater. Sci. 52 (2007) 540-596.

[26] L. Wondraczek, J.C. Mauro, J. Eckert, U. Kuhn, J. Horbach, J. Deubener, T. Rouxel, Adv. Mater. 23 (2011) $4578-4586$.

[27] F.D. Fischer, G. Reisner, E. Werner, K. Tanaka, G. Cailletaud, T. Antretter, Int. J. Plast. 16 (2000) 723-748.

[28] H.C. Shin, T.K. Ha, Y.W. Chang, Scr. Mater. 45 (2001) 823-829.

[29] A. Francois, P. Veyssiere, Intermetallics 2 (1994) 9-22.

[30] C.J. Li, J. Tan, X.K. Zhu, Y. Zhang, M. Stoica, U. Kühn, J. Eckert, Intermetallics 35 (2013) 116-119.

[31] C. Lall, M. Loretto, I. Harris, Acta Metall. 26 (1978) 1631-1641. 